\title{
Modelo de indicadores de gestão de pessoas em pequenas e médias empresas de
}

\section{construção}

\section{Model of people management indicators in small and medium building companies}

\author{
Vilmar Roque Pereira Mestre em Tecnologia e Gestão da Inovação. Universidade Comunitária \\ da Região de Chapecó e Sinduscon Oeste. \\ adm.vilmarpereira@hotmail.com \\ Marcelo Fabiano Costella Doutor em Engenharia de Produção. Universidade Comunitária da Região \\ de Chapecó e Faculdade Meridional. costella@unochapeco.edu.br \\ Francieli Dalcanton Mestra em Tecnologia e Gestão da Inovação. Universidade Comunitária \\ da Região de Chapecó. fdalcanton@unochapeco.edu.br
}

\section{RESUMO}

O objetivo deste artigo foi aplicar um modelo de indicadores de gestão de pessoas em pequenas e médias empresas da construção civil. A aplicação da pesquisa foi realizada em quatro empresas de construção civil, construtoras de edifícios residenciais, na cidade de Chapecó/SC. O modelo proposto teve como base o método de gestão de pessoas de Ivancevich. Inicialmente, foi realizado um diagnóstico nas empresas por meio de um questionário contendo 25 itens (cada item corresponde a uma atividade em gestão de pessoas). Em seguida, foram classificados 12 itens considerados mais importantes pelos gestores das empresas. Na sequência, foi definido o modelo de indicadores proposto contendo 12 procedimentos, instrumentos de medição (formulários padrões) e indicadores de desempenho. Finalmente realizou-se a aplicação prática do modelo com a participação do gestor de obra. Entre os resultados obtidos destaca-se o indicador de candidatos recrutados com o perfil da vaga desejada, no qual apenas $25 \%$ dos candidatos recrutados apresentaram o perfil desejado, o indicador de treinamento admissional mostrando que $100 \%$ dos candidatos contratados foram treinados e o indicador de verificação dos terceirizados revelando que, em uma das empresas pesquisadas, mais de $50 \%$ dos itens avaliados apresentaram não conformidade. Concluiu-se com esta pesquisa que as empresas da construção civil precisam adotar um modelo de gestão de pessoas estruturado com indicadores, havendo a participação de todos os envolvidos no processo.

Palavras-chave: Modelo de indicadores. Gestão de Pessoas. Gestor de Obras. Construção civil.

\begin{abstract}
This paper aimed to apply a model of people management indicators in small and medium construction companies. The application of the research was carried out in four construction companies that build residential buildings in the city of Chapecó / SC. The proposed model was based on Ivancevich people management method. Initially, a diagnosis was made in companies through a questionnaire containing 25 items (each item corresponds to an activity in people management). Then, 12 items considered most important by company managers were classified. Subsequently, the proposed indicator model containing 12 procedures, measuring instruments (standard forms) and performance indicators was defined. Finally, the practical application of the model was carried out with the participation of the construction manager. Among the results obtained, the indicator of candidates recruited with the desired vacancy profile stands out: only $25 \%$ of the recruited candidates presented the desired profile. Besides, the admission training indicator showed that $100 \%$ of the hired candidates were trained and the indicator of third-party verification revealed that, in one of the companies surveyed, more than $50 \%$ of the items evaluated showed non-compliance. The research led to the conclusion that construction companies need to adopt a people management model structured with indicators, with the participation of all involved in the process.
\end{abstract}

Keywords: Indicators model. People management. Construction. 


\section{INTRODUÇÃO}

A gestão de pessoas é o diferencial das empresas que almejam o sucesso. No entanto são poucos os estudos que tratam sobre este assunto na construção civil e os trabalhos desenvolvidos abordam apenas temas pontuais (BRANDENBURG; HAAS; BYROM, 2006; ZHAl; LIU; FELLOWS, 2014).

Além disso, as pequenas e médias empresas da construção civil possuem uma estrutura enxuta que, muitas vezes, dispensam profissionais especializados na área de gestão de pessoas, fazendo com que o gestor de obra também tome decisões de gestão de pessoas que seriam de competência do setor de recursos humanos (RH) (PEREIRA, 2018). Isto ocorre porque o setor de produção geralmente está distante dos setores administrativos da empresa, dificultando o contato entre as partes. Assim, o gestor de obra se torna o representante da empresa tomando as decisões com seus subordinados (RAJA et al., 2013; TAVARES; LONGO; SUETH, 2014; BOON; DEN HARTOG; LEPAK, 2019).

Os trabalhadores da construção civil geralmente eram pessoas de baixo grau de instrução ou qualificação técnica, aos quais se designava basicamente atividades braçais. Assim como os procedimentos de gestão eram baseados em conhecimentos empíricos, os gestores de obras eram escolhidos entre os membros do próprio grupo. Atualmente, o gestor de obras necessita de, pelo menos, uma formação técnica ou cursos específicos para capacitação neste cargo (BORGES; BRANDÃO; MARINHO, 2010; SALGADO, 2011, TAVARES; LONGO; SUETH, 2014; AMBERG; MCGAUGHEY, 2019).

Do mesmo modo que são raros estudos sobre gestão de pessoas na construção civil, a falta de políticas com a participação conjunta do gestor de $\mathrm{RH}$ e gestor de obras em todas as fases do processo dificulta a normatização de indicadores de desempenho que poderiam servir como ferramentas para a tomada de decisões. É preciso definir os papéis estratégicos para a gestão de pessoas, levando em consideração as particularidades deste setor (LAUFER, 1987; MARRAS, 2005; BICHUETTI, 2011; ZHAI; LIU; FELLOWS, 2014; MELEK, 2016; DEMO; FOGAÇA; COSTA, 2018).

Em função disso, o objetivo desse artigo foi apresentar e validar um modelo de indicadores de gestão de pessoas em pequenas e médias empresas da construção civil.

\section{GESTÃO DE PESSOAS NA CONSTRUÇÃO}

O referencial teórico consistiu em uma revisão de literatura que está descrita no método de pesquisa. Os tópicos desse referencial são apresentados conforme os processos básicos de gestão de pessoas de Chiavenato (2014). Ao final desse subcapítulo, é apresentado um quadro síntese da revisão de literatura.

\subsection{Processos de Agregar Pessoas}

Agregar pessoas refere-se à inclusão delas na organização. Raja et al. (2013) desenvolveu pesquisas em uma das maiores empresas de construção civil do Reino Unido apresentando as estratégias de gestão de recursos humanos em diferentes divisões operacionais da empresa, de como diferentes formas de contratação de funcionários influenciava na função de $\mathrm{RH}$, concluindo que o setor da construção precisa evoluir em suas práticas definindo papéis estratégicos.

A pesquisa realizada por Clarke e Herrmann (2007) averiguou as políticas de RH adotadas para recrutamento e retenção de funcionários frente à escassez de competências. Foi identificada que algumas estratégias são pouco utilizadas, predominando entre as empresas a formação e a promoção interna de funcionários e evidenciando a preferência por profissionais externos para substituição e preenchimento de vagas remanescentes. 


\subsubsection{Planejamento de Gestão de Recursos Humanos (PRH)}

Segundo Dom, Kasim e Shamsudin (2012), foram feitas entrevistas com especialistas que ocupam cargos gerenciais com experiência em planejamento de RH que influenciavam no fornecimento de mão de obra para a construção civil. Ao discutir questões da mão de obra local na indústria da construção da Malásia identificou-se a imprecisão no planejamento de RH nas empresas, carecendo de um sistema eficaz para a gestão de pessoas.

Laufer (1987) analisou os requisitos especiais de gestão de RH para a formação profissional de gestores da construção em faculdades de engenharia civil, tendo em vista que na construção civil, o custo de mão de obra é significativo no custo total de uma obra. O autor destaca a necessidade de capacitar continuamente os profissionais de engenharia em gestão de pessoas.

\subsection{Processos de Aplicar Pessoas}

Aplicar pessoas é ambientar novos funcionários nos processos da empresa. Brandenburg, Haas e Byrom (2006) apresentam os conceitos abordados e os procedimentos necessários para implementar uma estratégia de gestão da força do trabalho desenvolvida pelos Pesquisadores do Centro de Estudos da Indústria da Construção da Universidade do Texas em Austin, Estados Unidos. Embora existam estratégias e extensos programas disponíveis no Setor de Desenvolvimento de $\mathrm{RH}$, os autores reforçam sobre a importância de estratégias de gestão da força de trabalho nas empresas, independente do seu nível de habilidade.

\subsection{Processos de Recompensar Pessoas}

Recompensar é retribuir as pessoas pelos serviços prestados. Clarke e Herrmann (2007) verificaram que existe uma prática de aumento de salários de forma ordenada, embora muitas empresas ainda permaneçam confiando em métodos informais de remuneração. Os autores destacam que as empresas de construção civil apresentaram significativas diferenças na área de gestão de pessoas, que empresas do setor de habitação social possuem um maior número de empregos diretos, menos subcontratações, amplas políticas de recursos humanos e mais treinamentos.

\subsection{Processos de Desenvolver Pessoas}

Desenvolver é capacitar as pessoas ao perfil do cargo exercido. Brandenburg, Haas e Byrom (2006) enfatizam a importância de treinamento de pessoal, baseado na existência de poucos programas estruturados de gerenciamento de força de trabalho na indústria da construção. Os treinamentos são feitos on the job, provocado por poucos recursos disponíveis para a formação contínua e desenvolvimento da força de trabalho, relacionado à aprendizagem organizacional e gestão do conhecimento.

\subsubsection{Aprendizagem Organizacional}

Segundo Zhai, Liu e Fellows (2014), a aprendizagem organizacional é um componente importante da vantagem competitiva no processo de desenvolvimento organizacional, sendo essencial para aumentar a flexibilidade estratégica e de adaptação às mudanças da organização. O RH deve atuar como um assessor do departamento de produção, desenvolvendo ações estratégicas que contemplem ações de desenvolvimento organizacional. Além disso, as práticas de $\mathrm{RH}$ interferem também no desempenho financeiro da organização, bem como a satisfação de clientes e funcionários.

Dainty, Grugulis e Langford (2007) apresentam um resumo sobre o contexto do emprego na construção civil, identificando os desafios inerentes ao trabalho que tem impedido o desenvolvimento da gestão de $\mathrm{RH}$, bem como o melhoramento do desempenho da indústria. Os autores relatam que apesar dos 
avanços na tecnologia e gestão da produção, a construção civil é um dos setores mais dependentes de material humano.

\subsubsection{Gestão do Conhecimento}

De acordo com Esmi e Ennals (2009), há escassez de qualificação acadêmica e limitação na utilização da tecnologia da informação $(\mathrm{TI})$ nas empresas de construção, havendo a necessidade do compartilhamento de conhecimento tácito. Nas empresas no Reino Unido estão faltando trabalhadores qualificados, obrigando contratação de profissionais de outros países, os quais apresentam algumas dificuldades culturais.

Segundo Chen e Mohamed (2010) e Pathirage, Amaratunga e Haigh (2007), o conhecimento tácito é muito importante para a organização e a gestão do conhecimento deve levar este em consideração, pois através dele se atingem objetivos a longo prazo. Os estudos realizados, inclusive na construção civil, fornecem evidências empíricas sobre a gestão do conhecimento tácito em comparação com a gestão do conhecimento explícito. Os resultados demonstraram que a gestão do conhecimento tácito desempenha uma importante função para o processo de tomada de decisão estratégica da organização. Por estar intrínseco nas pessoas este conhecimento é um dos mais difíceis de ser gerido.

Chinowsky e Carrillo (2007) relataram a necessidade de as empresas de construção desenvolver a gestão do conhecimento e iniciativas de aprendizagem organizacional. A gestão do conhecimento deve ser ativa adaptando o conhecimento individual em informações que possam ser facilmente utilizadas pela organização como um todo. $O$ estudo demonstrou que há pouca pesquisa realizada sobre o tema na construção civil. As empresas que não apoiaram as iniciativas, além das fases iniciais da gestão do conhecimento, deixaram de aproveitar o potencial de uma aprendizagem organizacional.

\subsection{Processos de Manter Pessoas}

Manter pessoas é desenvolver ações que propiciem sua continuidade na organização. $O$ estudo desenvolvido por Laufer (1987) demonstrou a importância do clima organizacional nas empresas considerando que o contexto ambiental corresponde por aproximadamente $90 \%$ da variação do desempenho organizacional.

Brandenburg, Haas e Byrom (2006) também destacam a importância da supervisão e comunicação organizacional em todos os níveis hierárquicos. Os autores salientam que o supervisor é a ligação entre os funcionários operacionais e a direção da empresa, que a comunicação entre ambos deve ser regular e permitir que a informação nos dois sentidos possa fluir, que isto contribui para manter os trabalhadores na empresa, reduzindo as perdas de produtividade.

Clarke e Hermann (2007) observaram, com relação à retenção dos funcionários, que as iniciativas que se destacaram como diferencial nas empresas estudadas foram o treinamento e desenvolvimento de pessoal.

Brockman (2014) destaca que a forma como as pessoas se comportam dentro da organização é determinante para o sucesso dos trabalhos. $\mathrm{O}$ clima organizacional advém do relacionamento interpessoal. $\mathrm{O}$ autor salienta que são diversos os conflitos que ocorrem no canteiro de obra da construção civil, que os motivos de um conflito são os mais diversos possíveis, geralmente motivos banais.

\subsection{Processos de Monitorar Pessoas}

Monitorar pessoas são atividades desenvolvidas para controlar os trabalhos desenvolvidos. O estudo desenvolvido por Esmi e Ennals (2009) mostra que a partilha de conhecimentos é o diferencial para o ganho da produtividade, desenvolvimento de habilidades e aumento da produtividade. No entanto, os métodos de gestão do conhecimento são frágeis e incompletos, não havendo mecanismos para a captura, armazenamento e reutilização do conhecimento. Apesar de a tecnologia trazer informações avançadas, a construção civil tem se mantido conservadora na tomada de decisões em relação à gestão do conhecimento. 


\subsection{Quadro Síntese}

Os artigos foram sintetizados no Quadro 1 conforme o método de gestão de pessoas proposto por Chiavenato (2014). Pode-se observar que os artigos, com apenas uma exceção, foram realizados a partir de 2006, o que indica um campo de pesquisa recente.

Quanto aos autores e os locais de pesquisa, não foram encontrados artigos desenvolvidos no Brasil, o que demonstra a necessidade de pesquisas sobre o assunto da gestão de pessoas na construção no país. Constatou-se nos trabalhos estudados que os problemas encontrados pelos pesquisadores, a partir da experiência profissional dos autores desse artigo, são semelhantes àqueles constatados no dia a dia das empresas brasileiras. Isso leva a crer que, embora haja diferenças culturais, os aspectos comportamentais são comuns e que as necessidades neste setor são semelhantes nos diversos países, indiferente dos aspectos tecnológicos.

Quanto aos temas abordados pelos pesquisadores, percebeu-se que a maioria está concentrada nos processos de desenvolver pessoas. Apenas dois artigos abrangeram três processos e nenhum artigo abrangeu todos os processos de gestão de pessoas. Isso reforça a necessidade de desenvolver modelos mais abrangentes que contemplem todos os aspectos relacionados à gestão de pessoas desde a entrada até a saída do colaborador na empresa.

Quadro 1 - Síntese dos estudos encontrados na pesquisa.

\begin{tabular}{|c|c|c|c|c|c|c|c|}
\hline \multirow[b]{2}{*}{ Autores } & \multirow[b]{2}{*}{ Ano } & \multicolumn{2}{|c|}{ Processos de Processos de } & \multirow{2}{*}{$\begin{array}{c}\text { Processos de } \\
\text { Recompensar } \\
\text { Pessoas }\end{array}$} & \multirow{2}{*}{\begin{tabular}{|c|} 
Processos de \\
Desenvolver \\
Pessoas
\end{tabular}} & \multirow{2}{*}{$\begin{array}{c}\text { Processos de } \\
\text { Manter } \\
\text { Pessoas }\end{array}$} & \multirow{2}{*}{$\begin{array}{c}\text { Processos de } \\
\text { Monitorar } \\
\text { Pessoas }\end{array}$} \\
\hline & & $\begin{array}{l}\text { Agregar } \\
\text { Pessoas }\end{array}$ & $\begin{array}{l}\text { Aplicar } \\
\text { Pessoas }\end{array}$ & & & & \\
\hline Laufer & 1987 & $\mathrm{X}$ & & & & $x$ & \\
\hline $\begin{array}{c}\text { Brandenburg, Haas e } \\
\text { Byrom }\end{array}$ & 2006 & & $x$ & & $x$ & $x$ & \\
\hline Clarke e Herrmann & 2007 & $\mathrm{X}$ & & $\mathrm{X}$ & & $\mathrm{X}$ & \\
\hline Dainty, Grugulis e Langford & 2007 & & & & $\mathrm{X}$ & & \\
\hline $\begin{array}{c}\text { Pathirage; Amaratunga; } \\
\text { Haigh }\end{array}$ & 2007 & & & & $\mathrm{x}$ & & \\
\hline Chinowski e Carrillo & 2007 & & & & $x$ & & \\
\hline Esmi e Ennals & 2009 & & & & $\mathrm{X}$ & & $\mathrm{X}$ \\
\hline Chen e Mohamed & 2009 & & & & $\mathrm{X}$ & & \\
\hline Dom, Kasim, Shamsudin & 2012 & $\mathrm{X}$ & & & & & \\
\hline Raja et al. & 2013 & $\mathrm{X}$ & & & & & \\
\hline Zhai, Liu e Fellows & 2014 & & & & $\mathrm{X}$ & & \\
\hline Brockman & 2014 & & & & & $\mathrm{X}$ & \\
\hline Total & 12 & 4 & 1 & 1 & 7 & 4 & 1 \\
\hline
\end{tabular}

Fonte: Elaborado pelos autores (2019).

\section{MÉTODO DE PESQUISA}

A realização da pesquisa foi dividida em quatro fases: 1) Revisão sistemática da literatura; 2) Seleção das empresas; 3) Definição do modelo; 4) Aplicação do modelo.

\subsection{Revisão sistemática da literatura}

A revisão de literatura foi realizada utilizando o Portal de Periódicos Capes/MEC (http://www.periodicos.capes.gov.br), que buscou artigos publicados sobre gestão de pessoas na construção civil. Os critérios adotados para a seleção das publicações foram os publicados entre 1975 e 2017 em língua portuguesa e inglesa com as palavras-chave: "gestão de pessoas na construção civil" e "human resource management and construction industry". 
A busca palavra-chave "gestão de pessoas na construção civil" resultou em 537 artigos, dos quais todos foram rejeitados por não apresentaram relação com esta pesquisa. A busca com a palavra-chave "human resource management and construction industry" filtrou 490 artigos. Desses 490 artigos, através do resumo 22 deles foram selecionados, pois apresentavam alinhamento com esta pesquisa, sendo 12 artigos utilizados.

\subsection{Seleção das empresas}

Os critérios para a seleção das empresas foram: a) estar associada ao sindicato patronal Sinduscon/Oeste; b) ter obras em andamento durante o período da pesquisa; c) possuir o mínimo de 20 e o máximo 120 funcionários; d) ter a sede da empresa na cidade da pesquisa. Em seguida, o projeto de pesquisa foi apresentado em reunião à diretoria do Sinduscon/Oeste para a definição das empresas que participariam da pesquisa, as quais estão descritas no Quadro 2.

Quadro 2 - Empresas participantes da pesquisa

\begin{tabular}{|c|c|c|c|c|}
\hline Empresa & $\begin{array}{c}\text { Tempo de } \\
\text { existência (anos) }\end{array}$ & $\begin{array}{c}\text { No de } \text { duncionários } \\
\text { flassificação SEBRAE } \\
\text { (Número de } \\
\text { funcionários) }\end{array}$ & $\begin{array}{c}\text { Classificação BNDES } \\
\text { (Faturamento) }\end{array}$ \\
\hline A & 16 & 30 & Pequena & Pequena \\
\hline B & 29 & 126 & Média & Média \\
\hline C & 7 & 26 & Pequena & Pequena \\
\hline D & 24 & 32 & Pequena & Pena \\
\hline
\end{tabular}

Fonte: Elaborado pelos autores (2019).

\subsection{Definiç̧ão do modelo}

Esta seção apresenta o levantamento dos itens do modelo e seu respectivo detalhamento.

\subsubsection{Levantamento dos itens do modelo}

A definição do modelo proposto tomou como base o modelo de gestão de pessoas de Ivancevich (2010), apresentado na Figura 1, por abranger todos os processos de gestão de pessoas do subsistema de recursos humanos, contendo 25 itens. 
Figura 1 - Modelo de gestão de pessoas de Ivancevich

\begin{tabular}{|c|c|c|c|c|c|}
\hline \multicolumn{3}{|c|}{$\begin{array}{l}\text { Influências Ambientais Externas } \\
\text { - Exigências, normas e legislação governamentais } \\
\text { - Sindicatos } \\
\text { - Situação econômica/doméstica e internacional } \\
\text { - Competitividade } \\
\text { - Composição da força de trabalho } \\
\text { - Localização da organização }\end{array}$} & \multicolumn{3}{|c|}{ Influências Ambientais Internas } \\
\hline \\
\hline \multicolumn{6}{|c|}{ Processos de Recursos Humanos } \\
\hline $\begin{array}{l}\text { Aquisição de } \\
\text { Recursos Humanos } \\
\text { - Alinhamento e planeja- } \\
\text { mento } \\
\text { de recursos humanos } \\
\text { - Definição e análise de } \\
\text { cargos } \\
\text { - Recrutamento } \\
\text { - Seleção } \\
\text { - Orientação das pessoas }\end{array}$ & \multicolumn{2}{|c|}{$\begin{array}{l}\text { Compensação de } \\
\text { RecursosHumanos } \\
\text { - Modelagem do trabalho } \\
\text { - Avaliação de desem- } \\
\text { penho } \\
\text { - Compensação: métodos } \\
\text { e políticas } \\
\text { - Compensação: uma } \\
\text { visão geral } \\
\text { - Assistência e benefí- } \\
\text { cios aos funcionários }\end{array}$} & \multicolumn{2}{|c|}{$\begin{array}{l}\text { Desenvolvimento de } \\
\text { Recursos Humanos } \\
\text { - Treinamento e desen- } \\
\text { volvimento } \\
\text { - Desenvolvimento e } \\
\text { planejamento de } \\
\text { carreira }\end{array}$} & \begin{tabular}{|l|} 
Promoção da \\
Segurança e da Saúde \\
- Promoção da seguran- \\
ça e da saúde
\end{tabular} \\
\hline $\begin{array}{c}\text { Preocupação com as } \\
\text { pessoas e os resultados }\end{array}$ & \multicolumn{2}{|c|}{$\begin{array}{c}\text { Preocupação com as } \\
\text { pessoas e os resultados }\end{array}$} & \multicolumn{2}{|c|}{$\begin{array}{l}\text { Preocupação com as } \\
\text { pessoas e os resultados }\end{array}$} & \begin{tabular}{|c|} 
Preocupação com as \\
pessoas e os resultados
\end{tabular} \\
\hline \multicolumn{6}{|c|}{ Enfoque de cada processo concentrado nas pessoas e nos resultados } \\
\hline \multicolumn{3}{|c|}{ 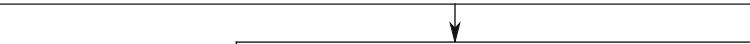 } & \multirow{2}{*}{\multicolumn{2}{|c|}{ Esperados $\downarrow$}} & \\
\hline & \multicolumn{2}{|c|}{ Resultados Finais Esperados } & & & \\
\hline & $\begin{array}{c}\text { Práticas éticas e } \\
\text { socialmente responsáveis }\end{array}$ & \multicolumn{2}{|c|}{$\begin{array}{c}\text { Produtos competitivos } \\
\text { de alta qualidade }\end{array}$} & $\begin{array}{l}\text { Serviços competitivos } \\
\text { de alta qualidade }\end{array}$ & $\begin{array}{l}\text { ivos } \\
\text { le }\end{array}$ \\
\hline
\end{tabular}

Fonte: Adaptado de Ivancevich (2010).

Em função do modelo de gestão de pessoas ser muito extenso, foi elaborado um questionário (Quadro 3) para realizar um diagnóstico nas empresas participantes da pesquisa. O objetivo do diagnóstico foi identificar quais eram, dentre as 25 atividades propostas por Ivancevich (2010), as de maior importância para serem contempladas no modelo de indicadores proposto. As opções de resposta do questionário foram definidas conforme a escala Likert, contendo cinco alternativas para cada questão (SAMPIERI; COLLADO; LUCIO, 2013).

O questionário foi aplicado individualmente com cada participante sob forma de entrevista, sendo que responderam ao questionário o proprietário e o responsável pelo $\mathrm{RH}$ de cada empresa (total de quatro empresas), totalizando 8 questionários. As respostas foram tabuladas e os dados foram ordenados e classificados em ordem crescente de porcentagem para cada item.

A partir da tabulação dos dados, foram selecionadas as atividades (questões) que apresentaram respostas com percentual maior ou igual a 75\%, como sendo "Muito Importante" e/ou "Extremamente Importante", totalizando 12 atividades (Quadro 3). As atividades classificadas compuseram o modelo de indicadores de gestão de pessoas proposto neste estudo. 
Quadro 3-Questionário de diagnóstico

\begin{tabular}{|c|c|c|c|c|c|c|}
\hline \multirow[t]{2}{*}{$\begin{array}{l}N^{\circ} \text { de } \\
\text { ordem }\end{array}$} & \multirow[t]{2}{*}{$\begin{array}{c}\text { Em relação à Gestão de Pessoas em sua empresa, defina o grau de } \\
\text { importância para cada uma das questões abaixo, assinalando sua resposta } \\
\text { em uma das colunas ao lado. }\end{array}$} & \multicolumn{5}{|c|}{$\begin{array}{c}1 \text { Nenhuma } \\
\text { importância } \\
2 \text { Pouca } \\
\text { importância } \\
3 \text { Importante } \\
4 \text { Muito } \\
\text { importante } \\
5 \text { Extremamente } \\
\text { importante }\end{array}$} \\
\hline & & 1 & 2 & 3 & 4 & 5 \\
\hline 1 & $\begin{array}{l}\text { Análise do perfil dos candidatos que se oferecem para trabalhar nas vagas } \\
\text { disponíveis na empresa }\end{array}$ & & & & & \\
\hline 2 & Definição prévia das características do candidato para a vaga disponível & & & & & \\
\hline 3 & $\begin{array}{l}\text { Procedimentos de recrutamento (divulgação de vagas, recebimento de } \\
\text { currículos de candidatos) }\end{array}$ & & & & & \\
\hline 4 & $\begin{array}{l}\text { Tempo transcorrido entre a identificação da necessidade de pessoal e a } \\
\text { finalização da contratação }\end{array}$ & & & & & \\
\hline 5 & $\begin{array}{l}\text { Procedimentos utilizados na seleção dos candidatos (entrevista, avaliações, } \\
\text { testes teóricos, testes práticos) }\end{array}$ & & & & & \\
\hline 6 & Realização de reuniões de integração com o novo funcionário & & & & & \\
\hline 7 & Delegação de tarefas do gestor de obra aos seus colaboradores & & & & & \\
\hline 8 & $\begin{array}{l}\text { Fazer avaliação de desempenho de forma sistemática com cada funcionário } \\
(f e e d b a c k) \text {, durante e após o período de experiência }\end{array}$ & & & & & \\
\hline 9 & $\begin{array}{l}\text { Aplicação de treinamentos ministrados pelo gestor de obra, aos seus } \\
\text { colaboradores, no canteiro de obras }\end{array}$ & & & & & \\
\hline 1 & Envolvimento do gestor de obra na definição das normas internas da empresa & & & & & \\
\hline 11 & $\begin{array}{l}\text { Comprometimento do gestor de obra na fiscalização do cumprimento das } \\
\text { normas internas }\end{array}$ & & & & & \\
\hline 12 & $\begin{array}{l}\text { Envolvimento do gestor de obra nos trabalhos de gestão dos terceirizados } \\
\text { (cumprimento das normas internas, fiscalização dos trabalhos, medições) }\end{array}$ & & & & & \\
\hline
\end{tabular}

Fonte: Elaborado pelos autores (2019).

\subsubsection{Detalhamento dos itens do modelo}

A definição do modelo proposto sugeriu uma nova forma de execução dos trabalhos descrevendo os procedimentos a serem tomados para realizar cada atividade contendo indicadores, fórmulas de cálculo e periodicidade de monitoramento. Os itens contemplados no modelo foram definidos por especialistas em gestão de pessoas, determinando-se uma nova forma de realização de cada atividade, com fundamento em bibliografias de diversos autores nacionais e internacionais. Para a realização de cada atividade foi sugerido um procedimento padrão, formulários para registro dos dados, fórmula de cálculo para geração dos indicadores e planilhas para monitoramento dos resultados. O conhecimento acadêmico e o know-how em gestão de pessoas adquiridos pela experiência profissional do pesquisador em empresas de diversos ramos de atividade, contribuíram para a elaboração do modelo proposto.

\subsection{Aplicação do modelo}

A aplicação do modelo foi feita através da execução dos procedimentos conforme estabelecidos, sugerindo nova forma de realização das atividades, fazendo acompanhamento in loco efetuando os registros dos dados. O monitoramento dos resultados ocorreu através do acompanhamento dos trabalhos desenvolvidos nos setores, verificando o registro das informações geradas durante a realização das atividades, certificando-se da forma correta de aplicação conforme orientação previa do pesquisador aos responsáveis pelas atividades. As informações foram registradas pelos responsáveis das respectivas atividades conforme orientação do pesquisador. A análise dos indicadores foi feita individualmente para cada atividade implantada, comparando os dados obtidos de cada empresa. Os dados foram tabulados em planilhas eletrônicas, conforme a aplicação dos procedimentos do modelo proposto. Os setores das empresas diretamente envolvidos na pesquisa foram recursos humanos, segurança do trabalho e produção de obras, nos quais o pesquisador realizava visitas periódicas semanais mantendo contato com seus respectivos responsáveis. 


\section{MODELO DE INDICADORES DE GESTÃO DE PESSOAS}

O Quadro 4 apresenta os 12 itens contemplados no modelo proposto, os procedimentos padrões, instrumentos de medição (formulários padrões), indicadores de desempenho para cada atividade, fórmula de cálculo e a periodicidade de medição dos resultados para cada indicador.

Quadro 4 - Modelo de indicadores de gestão de pessoas proposto

\begin{tabular}{|c|c|c|c|c|}
\hline $\begin{array}{c}\text { Relação das } \\
\text { Atividades }\end{array}$ & \begin{tabular}{|c|} 
Procedimento \\
padrão
\end{tabular} & Indicador & Fórmula de cálculo & \begin{tabular}{|l}
$\begin{array}{l}\text { Periodi } \\
\text { cidade }\end{array}$ \\
\end{tabular} \\
\hline $\begin{array}{l}\text { Procedimentos } \\
\text { de recrutamento } \\
\text { (divulgação de } \\
\text { vagas, } \\
\text { recebimento de } \\
\text { currículos de } \\
\text { candidatos) } \\
\end{array}$ & Ficha Cadastral & $\begin{array}{l}\text { Número de } \\
\text { candidatos } \\
\text { recrutados }\end{array}$ & $\begin{array}{c}\text { NCR }=\text { NSUM - NSPM } \\
\text { NCR: Número de candidatos recrutados no mês. } \\
\text { NSUM: Número sequencial no último dia do mês (é o } \\
\text { número da última ficha cadastral preenchida no mês). } \\
\text { NSUMA: Número sequencial no último dia do mês anterior } \\
\text { (é o número da última ficha cadastral preenchida no mês } \\
\text { anterior). }\end{array}$ & Mensal \\
\hline $\begin{array}{c}\text { Análise do perfil } \\
\text { dos candidatos } \\
\text { que se oferecem } \\
\text { para trabalhar nas } \\
\text { vagas disponíveis } \\
\text { na empresa }\end{array}$ & Ficha Cadastral & $\begin{array}{l}\text { Percentual de } \\
\text { candidatos } \\
\text { com perfil } \\
\text { para a vaga } \\
\text { pretendida }\end{array}$ & $\begin{array}{c}\text { \% CP }=\frac{N C P}{N C R} \boldsymbol{X} 100 \\
\text { \%CP: Percentual de candidatos com o perfil da vaga, } \\
\text { recrutados no mês. } \\
\text { NCP: Número de candidatos com o perfil da vaga } \\
\text { recrutados no mês (considera-se candidatos com } \\
\text { perfil da vaga, os que atendem às competências } \\
\text { exigidas para o cargo conforme descrito no Manual } \\
\text { de Cargos e Funções } \\
\text { NCR: Número de candidatos recrutados no mês (é obtido } \\
\text { através da contagem do número de Fichas } \\
\text { Cadastrais preenchidas mensalmente, entre o } \\
\text { primeiro e o último dia do mês). }\end{array}$ & Mensal \\
\hline $\begin{array}{c}\text { Definição prévia } \\
\text { das características } \\
\text { do candidato } \\
\text { para a vaga } \\
\text { disponível }\end{array}$ & $\begin{array}{l}\text { Solicitação para } \\
\text { Contratação de } \\
\text { Funcionário }\end{array}$ & $\begin{array}{l}\text { Percentual de } \\
\text { funcionários } \\
\text { contratados } \\
\text { com o perfil } \\
\text { desejado }\end{array}$ & $\begin{array}{c}\% \boldsymbol{F C D}=\frac{\boldsymbol{N F C D}}{\boldsymbol{N F \boldsymbol { A }}} \boldsymbol{X} \mathbf{1 0 0} \\
\text { \%FCD: Percentual de funcionários com definição prévia das } \\
\text { características contratados no mês. } \\
\text { NFCD: Número de funcionários contratados com definição } \\
\text { prévia das características no mês. } \\
\text { NFA: Número de funcionários admitidos no mês (obtido } \\
\text { através de relatório contábil fornecido pelo setor } \\
\text { de RH com o total de funcionários admitidos no } \\
\text { mês). }\end{array}$ & Mensal \\
\hline $\begin{array}{l}\text { Tempo } \\
\text { transcorrido entre } \\
\text { a identificação da } \\
\text { necessidade de } \\
\text { pessoal e a } \\
\text { finalização da } \\
\text { contratação }\end{array}$ & $\begin{array}{c}\text { Solicitação para } \\
\text { Contratação de } \\
\text { Funcionário }\end{array}$ & $\begin{array}{l}\text { Percentual de } \\
\text { funcionários } \\
\text { contratados } \\
\text { no prazo } \\
\text { determinado }\end{array}$ & $\begin{array}{c}\% \boldsymbol{F C P}=\frac{\boldsymbol{N F C P}}{\boldsymbol{N F \boldsymbol { A }} \boldsymbol{X} \mathbf{1 0 0}} \\
\text { \%FCP: Percentual de funcionários contratados conforme a } \\
\text { previsão no mês. } \\
\text { NFCP: Número de funcionários contratados conforme a } \\
\text { previsão no mês (identificado na Solicitação de } \\
\text { Contratação de Funcionário). } \\
\text { NFA: Número de funcionários admitidos no mês (obtido } \\
\text { através de relatório contábil). }\end{array}$ & Mensal \\
\hline \multirow[t]{2}{*}{$\begin{array}{l}\text { Procedimentos } \\
\text { utilizados na } \\
\text { seleção dos } \\
\text { candidatos } \\
\text { (entrevista, } \\
\text { avaliações, testes } \\
\text { teóricos, testes } \\
\text { práticos) }\end{array}$} & $\begin{array}{l}\text { Roteiro de } \\
\text { Seleção }\end{array}$ & $\begin{array}{l}\text { Percentual de } \\
\text { candidatos } \\
\text { aprovados }\end{array}$ & \begin{tabular}{|c} 
\% CA $=\frac{\boldsymbol{N C S}}{\boldsymbol{N C R}} \boldsymbol{X} \mathbf{1 0 0}$ \\
\%CA: $\quad$ Percentual de candidatos aprovados no processo \\
de seleção no mês. \\
NCS: Número de candidatos selecionados no processo \\
de seleção no mês (obtido através da contagem de \\
candidatos aprovados conforme a Solicitação de \\
Contratação de Funcionário). \\
NCR: Número de candidatos recrutados (obtido através \\
do total de Fichas Cadastrais do banco de dados daquele \\
cargo específico, cadastradas nos últimos três meses).
\end{tabular} & Mensal \\
\hline & $\begin{array}{l}\text { Avaliação de } \\
\text { Desempenho }\end{array}$ & $\begin{array}{l}\text { Percentual de } \\
\text { funcionários } \\
\text { efetivados } \\
\text { após o }\end{array}$ & $\begin{array}{l}\% F E=\frac{N F E}{N F A} X 100 \\
\begin{array}{c}\% F E: \text { Percentual de funcionários efetivados após o período } \\
\text { de experiência no mês. }\end{array}\end{array}$ & Mensal \\
\hline
\end{tabular}




\begin{tabular}{|c|c|c|c|c|}
\hline & & $\begin{array}{l}\text { período de } \\
\text { experiência }\end{array}$ & $\begin{array}{l}\text { NFE: Número de funcionários efetivados no mês (obtido } \\
\text { através do formulário de Avaliação de Desempenho, } \\
\text { preenchido no término do contrato de experiência). } \\
\text { NFA: Número de funcionários admitidos com período de } \\
\text { experiência vencendo no mês (obtido através de relatório } \\
\text { contábil com o total de funcionários admitidos no mês). }\end{array}$ & \\
\hline $\begin{array}{l}\text { Realização de } \\
\text { reuniões de } \\
\text { integração com } \\
\text { o novo } \\
\text { funcionário }\end{array}$ & $\begin{array}{l}\text { Treinamentos } \\
\text { de integração }\end{array}$ & $\begin{array}{l}\text { Percentual } \\
\text { de } \\
\text { funcionários } \\
\text { que fizeram } \\
\text { treinamento }\end{array}$ & $\begin{array}{l}\qquad \% F T=\frac{N F T}{N F A} X 100 \\
\text { oFT: Percentual de funcionários treinados no mês. } \\
\text { NFT: Número de funcionários treinados no mês } \\
\text { (obtido através da contagem de Registros de } \\
\text { Treinamento Admissional emitidos no mês). } \\
\text { NFA: Número de funcionários admitidos no mês } \\
\text { (obtido através de relatório contábil com o total de } \\
\text { funcionários admitidos no mês). }\end{array}$ & Mensal \\
\hline $\begin{array}{l}\text { Delegação de } \\
\text { tarefas do } \\
\text { gestor de obra } \\
\text { aos seus } \\
\text { colaboradores }\end{array}$ & $\begin{array}{l}\text { Planilha de } \\
\text { delegação de } \\
\text { tarefas }\end{array}$ & $\begin{array}{l}\text { Percentual } \\
\quad \text { de } \\
\text { atividades } \\
\text { realizadas }\end{array}$ & $\begin{array}{l}\qquad \% A R=\frac{N A R}{N A D} X 100 \\
\text { \%AR: Percentual de atividades realizadas. } \\
\text { NAR: Número de atividades realizadas. (obtido } \\
\text { através da contagem das atividades realizadas } \\
\text { conforme o formulário Atividades Delegadas X } \\
\text { Atividades Realizadas). } \\
\text { NAD: Número de atividades delegadas. (obtido } \\
\text { através da contagem das atividades realizadas). }\end{array}$ & Mensal \\
\hline $\begin{array}{c}\text { Fazer avaliação } \\
\text { de } \\
\text { desempenho } \\
\text { de forma } \\
\text { sistemática com } \\
\text { cada } \\
\text { funcionário } \\
\text { (feedback), } \\
\text { durante e após } \\
\text { o período de } \\
\text { experiência }\end{array}$ & $\begin{array}{l}\text { Avaliação de } \\
\text { Desempenho }\end{array}$ & $\begin{array}{l}\text { Percentual } \\
\text { de } \\
\text { funcionários } \\
\text { que fizeram } \\
\text { avaliação de } \\
\text { desempenh } \\
\text { o }\end{array}$ & $\begin{array}{l}\text { \%FA }=\frac{N F A}{N F T} X 100 \\
\text { \%FA: Percentual de funcionários avaliados no } \\
\text { semestre (calculado semestralmente, com todos os } \\
\text { funcionários, nos meses de março e setembro). } \\
\text { NFA: Número de funcionários avaliados (obtido } \\
\text { através do total de avaliações feitas no mês da } \\
\text { avaliação). } \\
\text { NFT: Número de funcionários trabalhando no mês } \\
\text { (corresponde ao total de funcionários trabalhando no } \\
\text { mês da avaliação, obtido através do relatório de } \\
\text { empregados fornecido pelo RH). }\end{array}$ & $\begin{array}{l}\text { Semes- } \\
\text { tral }\end{array}$ \\
\hline $\begin{array}{c}\text { Aplicação de } \\
\text { treinamentos } \\
\text { ministrados } \\
\text { pelo gestor de } \\
\text { obra, aos seus } \\
\text { colaboradores, } \\
\text { no canteiro de } \\
\text { obras } \\
\end{array}$ & $\begin{array}{c}\text { Plano de } \\
\text { Treinamentos }\end{array}$ & $\begin{array}{c}\text { Horas de } \\
\text { treinamento } \\
\text { por } \\
\text { funcionário }\end{array}$ & $\begin{array}{l}\qquad H T F=\frac{N H T X N F T}{N T F} \\
\text { HTF: Horas de treinamento por funcionário. } \\
\text { NHT: Número de horas de treinamento no semestre } \\
\text { NFT: Número de funcionários treinados no semestre. } \\
\text { NTF: Número total de funcionários registrados. }\end{array}$ & $\begin{array}{l}\text { Semes- } \\
\text { tral }\end{array}$ \\
\hline $\begin{array}{l}\text { Envolvimento } \\
\text { do gestor de } \\
\text { obra na } \\
\text { definição das } \\
\text { normas internas } \\
\text { da empresa }\end{array}$ & $\begin{array}{l}\text { Manual de } \\
\text { normas } \\
\text { internas }\end{array}$ & $\begin{array}{l}\text { Percentual } \\
\text { de } \\
\text { participação } \\
\text { do gestor na } \\
\text { definição } \\
\text { das normas }\end{array}$ & $\begin{array}{l}\qquad \% P G=\frac{N R S}{N T R} X 100 \\
\text { \%PG: Percentual de participação do gestor. } \\
\text { NRS: Número de respostas "Sim" do Lista de } \\
\text { Verificação (aplicada semestralmente). } \\
\text { NTR: Número total de respostas da Lisa de Verificação } \\
\text { (aplicada semestralmente). }\end{array}$ & $\begin{array}{c}\text { Semes- } \\
\text { tral }\end{array}$ \\
\hline $\begin{array}{l}\text { Comprometime } \\
\text { nto do gestor } \\
\text { de obra na } \\
\text { fiscalização do } \\
\text { cumprimento } \\
\text { das normas } \\
\text { internas }\end{array}$ & $\begin{array}{l}\text { Descritivo de } \\
\text { cargo do } \\
\text { gestor de obra }\end{array}$ & $\begin{array}{l}\text { Número de } \\
\text { ocorrências } \\
\text { por } \\
\text { descumprim } \\
\text { ento de } \\
\text { normas }\end{array}$ & $\begin{array}{c}\text { Número absoluto de ocorrências mensal por } \\
\text { descumprimento das normas internas, registradas } \\
\text { conforme a Lista de Verificação da Obra. }\end{array}$ & Mensal \\
\hline $\begin{array}{l}\text { Envolvimento } \\
\text { do gestor de } \\
\text { obra nos } \\
\text { trabalhos de } \\
\text { gestão dos }\end{array}$ & $\begin{array}{l}\text { Descritivo de } \\
\text { cargo do } \\
\text { gestor de } \\
\text { obra, }\end{array}$ & $\begin{array}{l}\text { Número de } \\
\text { ocorrências } \\
\text { por } \\
\text { descumprim }\end{array}$ & $\begin{array}{l}\text { Número absoluto de ocorrências mensal por } \\
\text { descumprimento das normas internas, registradas } \\
\text { conforme a Lista de Verificação de Terceirizados. }\end{array}$ & Mensal \\
\hline
\end{tabular}




\begin{tabular}{|c|c|c|l|l|}
\hline terceirizados & Manual de & ento de & \\
(cumprimento & $\begin{array}{c}\text { gestão de } \\
\text { das normas } \\
\text { terceiros }\end{array}$ & normas & \\
internas, & & & \\
fiscalização dos & & \\
trabalhos, & & & \\
medições) & & & \\
\hline
\end{tabular}

Fonte: Elaborado pelos autores (2019).

\section{APLICAÇÃO DO MODELO}

A aplicação do modelo é apresentada nessa seção para os 12 indicadores de gestão de pessoas propostos.

\subsection{Procedimentos de recrutamento (divulgação de vagas, recebimento de currículos de candidatos)}

Os resultados obtidos com a padronização dos procedimentos de recrutamento são apresentados na Figura 2.

Figura 2 - Número de candidatos recrutados por mês por empresa no período da pesquisa

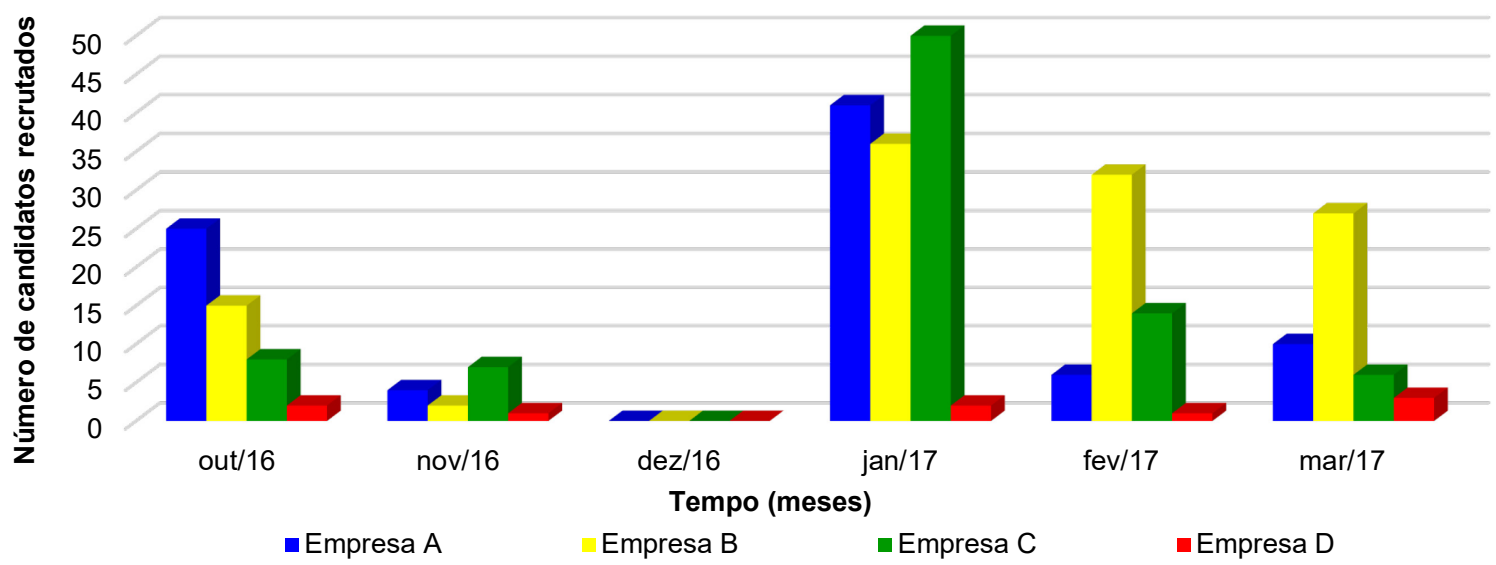

Fonte: Elaborado pelos autores (2019).

Por meio da tabulação dos nomes dos candidatos recrutados, identificou-se que alguns candidatos procuraram emprego em mais de uma empresa participante da pesquisa. Percebeu-se também que a maior parte dos candidatos são ex-funcionários de empresas da construção civil, procurando trabalho em empresas do mesmo ramo, sendo poucos candidatos recrutados de outros segmentos. Observou-se que, em algumas empresas, havia pouca preocupação dos recrutadores/responsáveis pelo RH em fazer recrutamento de pessoal para formação de banco de dados, quando não havia vaga disponível. Em alguns casos, os responsáveis pelo recrutamento nas empresas, mesmo tendo sido orientados a seguirem o procedimento padrão sugerido para fazer o recrutamento (preencher a Ficha Cadastral), permaneceram utilizando o procedimento informal costumeiramente utilizado, tais como: receber currículos com informações parciais do candidato, anotar apenas informações básicas do candidato em uma folha de papel.

\subsection{Análise do perfil dos candidatos que se oferecem para trabalhar nas vagas disponíveis na empresa}

Na Figura 3 observa-se que a média de candidatos recrutados com perfil desejado em todas as empresas no período da pesquisa foi de $25 \%$. A diferença apresentada entre as Empresas C e D talvez se justifique pela rigorosidade dos critérios de seleção adotados pelo gestor de RH. Observou-se ainda que na 
Empresa $\mathrm{D}$, o responsável pelo $\mathrm{RH}$ no ato do preenchimento/entrega da ficha cadastral, imediatamente conversava com o candidato fazendo uma pré-seleção do mesmo, tanto verbal, quanto na observação das informações registradas na ficha cadastral, obtendo de forma imediata as informações necessárias para a classificação do candidato. Na Empresa C, a qual obteve o maior índice de candidatos recrutados com o perfil desejado, observou-se que o procedimento de pré-seleção era feito somente através da análise das informações da ficha cadastral. O contato com o candidato no ato do preenchimento/entrega da ficha cadastral era realizado por outra pessoa (geralmente a pessoa que trabalha na recepção da empresa). O responsável pelo $\mathrm{RH}$ raramente conversava com o candidato no ato do preenchimento/recebimento da ficha cadastral.

Figura 3 - Percentual médio de candidatos recrutados com perfil por empresa durante a pesquisa

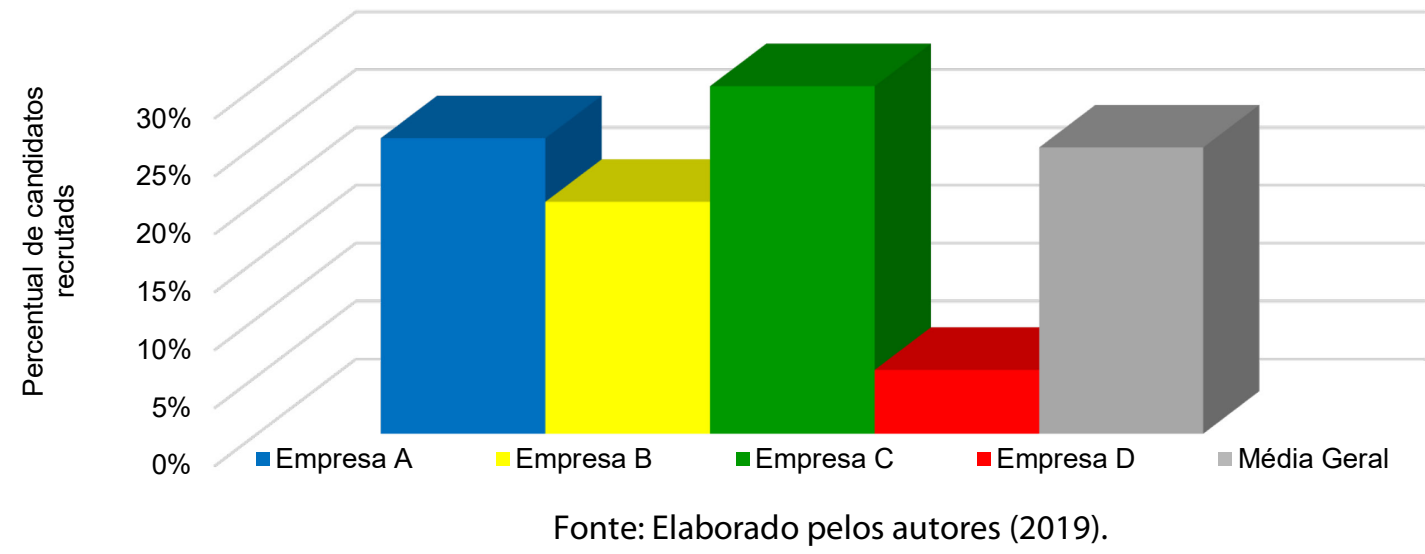

É importante observar que o índice de candidatos com perfil adequado ao cargo desejado apresentou-se baixo, sendo que este processo é o ponto de partida para o início do processo de contratação de novos empregados na organização. Daí a importância da análise do recrutador na pré-seleção dos candidatos através da observação das fichas cadastrais (triagem) estar baseada em informações coerentes para evitar o descarte de fichas cadastrais de candidatos com perfil adequado. Da mesma forma, é muito importante que o gestor especifique na solicitação de contratação de funcionário todas as informações do perfil do candidato para a vaga em aberto, para evitar a omissão de informações que possam implicar na pré-seleção de candidatos sem o perfil ou na desclassificação indevida de candidatos. Esta análise de perfil se tratava de uma pré-seleção (triagem) dos candidatos pela análise curricular, realizada através da observação dos requisitos mínimos exigidos pelo cargo.

Quanto aos critérios de seleção, observou-se durante a pesquisa que havia um requisito informal adotado pelos recrutadores, que é o tempo de permanência do candidato nos empregos anteriores. Embora fosse um critério subjetivo este procedimento era comum entre as empresas pesquisadas, não sendo considerado quando o selecionador conhecia a vida profissional pregressa do candidato, sabendo os motivos da curta duração nos empregos anteriores.

\subsection{Definição prévia da característica do candidato para a vaga disponível}

Em todas as contratações efetuadas no período da pesquisa não foi utilizado o procedimento para definição prévia das características do empregado pelo gestor da obra, embora os gestores de obras e os gestores de $\mathrm{RH}$ tenham sido orientados sobre este procedimento, o qual fez parte do modelo proposto.

Verificou-se neste período que as contratações efetuadas foram para vagas no canteiro de obras, que as solicitações de contratação foram feitas pelos gestores de obra (os quais eram engenheiros ou encarregados), porém este procedimento ocorreu de maneira informal ignorando a utilização do procedimento sugerido; de forma verbal o gestor responsável pela obra repassava ao responsável pelo $\mathrm{RH}$ as 
informações necessárias para contratação. Embora as vagas em aberto no período tenham sido para cargos operacionais (servente, carpinteiro, pedreiro), percebeu-se que, mesmo verbalmente, raramente houve descrição detalhada das características que o candidato deveria apresentar para ser selecionado. Segundo informações dos gestores de $\mathrm{RH}$, para contratação de pessoal para cargos mais específicos tais como gestor de obra, o processo seletivo seria mais diligente, porém da mesma forma as informações sobre as vagas seriam verbais. Percebeu-se que a não utilização do procedimento sugerido ocorreu devido à dificuldade de alguns gestores em formalizar suas ações, resistindo à mudança cultural.

\subsection{Tempo transcorrido entre a identificação da necessidade de pessoal e a finalização da contratação}

Em todas as empresas verificou-se que nenhuma admissão foi realizada com definição de data limite para a contratação pelo gestor de obra, conforme as orientações repassadas pelo modelo proposto; isto é, os gestores de obra ao solicitar nova contratação ao $\mathrm{RH}$, não utilizaram o formulário de solicitação de contratação de pessoal especificando a data limite para admissão. Isso demonstrou a dificuldade da mudança cultural dos gestores para a adoção de novos procedimentos, mesmo que as ações sugeridas tenham sido de baixa complexidade, exigindo apenas a formalização dos procedimentos. Soma-se a isso, o grau de dificuldade que alguns gestores apresentaram em registrar formalmente alguns procedimentos, uma vez que as atividades cotidianas se resumiram em ações informais.

\subsection{Procedimentos utilizados na seleção dos candidatos (entrevista, avaliações, testes teóricos, testes} práticos)

Observa-se na Figura 4, que durante o período de pesquisa foram recrutados 293 candidatos, dos quais 137 apresentaram o perfil para vaga pretendida, sendo que apenas 27 candidatos foram aprovados no processo seletivo. Percebeu-se que neste período o mercado de recursos humanos (candidatos disponíveis para contratação) esteve com alta demanda em relação ao mercado de trabalho (número de vagas disponíveis nas empresas).

Figura 4 - Número de candidatos recrutados, candidatos com perfil e candidatos selecionados

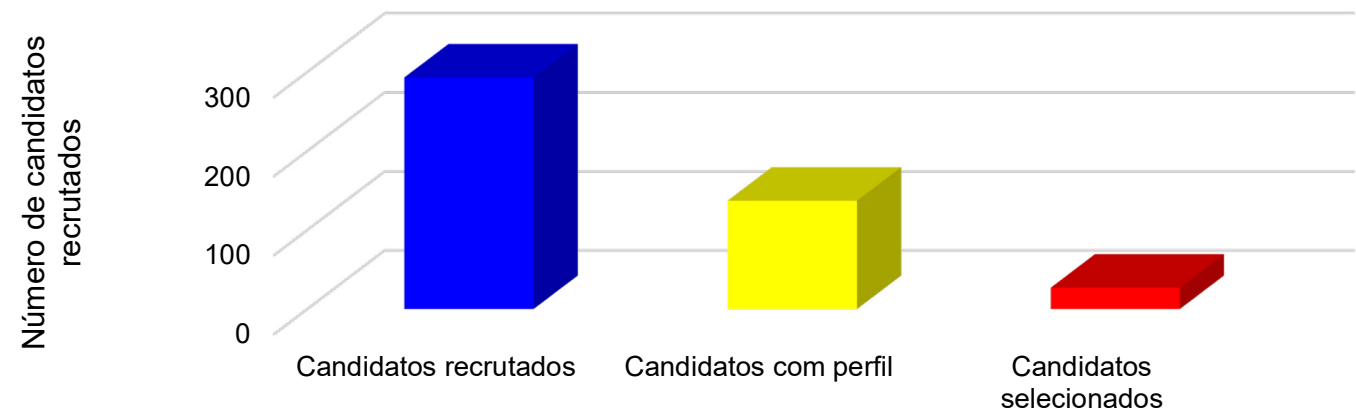

Fonte: Elaborado pelos autores (2019).

Uma prática observada durante o período da pesquisa, que interfere diretamente na diminuição do percentual de candidatos selecionados, foi que, em algumas empresas, quando surgia a necessidade de contratação de pessoal, por não haver um sistema de gestão de pessoas estruturado, o próprio gestor de obra ou os funcionários da empresa indicavam os candidatos para serem admitidos, os quais não eram submetidos aos procedimentos formais de recrutamento e seleção.

Salienta-se que o processo de seleção de empregados não termina com a formalização da contratação do empregado, exceto quando este é admitido sem contrato de experiência. O período de experiência é uma continuação do processo seletivo, o qual se encerra com a efetivação do empregado após o término do 
contrato de experiência. Durante esse período o gestor de obras avalia a adaptação do novo empregado, formalizando sua avaliação no término de contrato de experiência. Durante o período da pesquisa, em todas as empresas os empregados contratados foram aprovados no período de experiência, significando de que houve adaptação no trabalho.

\subsection{Realização de reuniões de integração com o novo funcionário}

Nos meses em que houve admissão de funcionários, em todas as empresas, todos os funcionários admitidos foram treinados. Os treinamentos foram ministrados pelo técnico em segurança no trabalho com orientações verbais e uso de recursos audiovisuais. Os assuntos abordados basicamente referiam-se às normas de segurança baseados na NR-18 (BRASIL, 2018), normas internas, histórico da empresa e cultura da organização. Não foi realizada a entrega de material aos novos funcionários (manuais de integração) contendo as informações do treinamento.

A participação do responsável pelo RH nos treinamentos admissionais não ocorreu em todas as empresas, sendo que as funções deste se resumiam a procedimentos burocráticos, tais como registros do empregado no sistema e emissão de documentos. O gestor de obra não participou do processo de recrutamento e seleção, nem do treinamento de integração. As informações básicas sobre o setor de trabalho eram repassadas ao novo empregado de maneira informal, no ato do início das atividades, sendo neste momento o primeiro contato do gestor de obras com o novo funcionário; exceto quando o novo funcionário era um indicado do gestor de obras, o qual encaminhava o candidato ao setor de $\mathrm{RH}$ para os procedimentos admissionais.

\subsection{Delegação de tarefas do gestor de obra aos seus colaboradores}

Percebeu-se que os gestores de obra não possuíam sistema formal para registro das atividades delegadas e/ou realizadas, as quais eram discutidas e delegadas verbalmente sem qualquer indicador quanto à sua eficácia. $O$ cronograma de execução da obra, contendo somente as atividades de longo prazo, era fixado na parede do escritório da obra; a partir daí, não havia um cronograma detalhado com as atividades de médio e curto prazo, nem a confrontação do planejado com o realizado. Embora algumas etapas da obra fossem concluídas em tempo menor que o estimado no cronograma, não havia registro detalhado do número de dias ou homens-hora utilizados na execução dos trabalhos.

O procedimento sugerido propôs uma prática formal de registro das atividades da obra servindo como indicador de produtividade. De maneira geral, percebeu-se a dificuldade da implementação deste procedimento que exigia controles e formalizações pelo gestor da obra, até mesmo nas empresas havia sistema de gestão da qualidade certificado.

\subsection{Fazer avaliação de desempenho de forma sistemática de cada funcionário (feedback), durante e após o período de experiência}

Nas empresas em que houve avaliação de desempenho, ela foi realizada com todos os empregados da obra. Na Empresa C em que o gestor de obras aplicou a avaliação de desempenho nos meses de outubro e dezembro (Quadro 5), verificou-se melhoria nos resultados da maioria dos empregados. Percebeu-se que o gestor de obra fez a avaliação de maneira formal conversando individualmente com cada subordinado, justificando o conceito aplicado em cada item, seguindo as orientações do pesquisador. 
Quadro 5 - Resultado a Aplicação da Avaliação de Desempenho na "Empresa C"

\begin{tabular}{|c|c|c|c|c|c|c|c|c|c|c|c|c|c|c|c|c|c|c|c|c|c|c|c|c|c|c|c|}
\hline \multirow{2}{*}{$\begin{array}{l}\text { Mês } \\
\text { da } \\
\text { avalía } \\
\text { ção }\end{array}$} & \multirow{2}{*}{$\begin{array}{l}\text { Nome } \\
\text { do } \\
\text { funcio- } \\
\text { nário }\end{array}$} & \multirow{2}{*}{$\begin{array}{l}\mathbf{C} \\
\mathbf{a} \\
\mathbf{r} \\
\mathbf{g} \\
\mathbf{0}\end{array}$} & \multicolumn{5}{|c|}{$\begin{array}{c}\text { Relacionamento } \\
\text { Interpessoal }\end{array}$} & \multicolumn{5}{|c|}{ Produtividade } & \multicolumn{5}{|c|}{$\begin{array}{l}\text { Cumprimentos } \\
\text { das Normas de } \\
\text { Segurança }\end{array}$} & \multicolumn{5}{|c|}{ Assiduidade } & \multicolumn{5}{|c|}{ Iniciativa } \\
\hline & & & $\mathbf{R}$ & $\begin{array}{l}R \\
\text { E }\end{array}$ & B & $\begin{array}{l}\text { M } \\
\text { B }\end{array}$ & 0 & $\mathbf{R}$ & $\begin{array}{l}\mathbf{R} \\
\mathbf{E}\end{array}$ & B & $\begin{array}{l}\text { M } \\
\text { B }\end{array}$ & 0 & $\mathbf{R}$ & $\begin{array}{l}\text { R } \\
\text { E }\end{array}$ & B & \begin{tabular}{|l|} 
M \\
B
\end{tabular} & 0 & $\mathbf{R}$ & \begin{tabular}{|l|}
$\mathbf{R}$ \\
$\mathbf{E}$ \\
\end{tabular} & B & $\begin{array}{l}\text { M } \\
\mathbf{B}\end{array}$ & 0 & $\mathbf{R}$ & \begin{tabular}{l|}
$\mathbf{R}$ \\
$\mathbf{E}$
\end{tabular} & B & $\begin{array}{l}\text { M } \\
\text { B }\end{array}$ & 0 \\
\hline out & AAA & 1 & & & $\mathrm{X}$ & & & & & & $\mathrm{X}$ & & & & & $\mathrm{X}$ & & & & & $x$ & & & & & $\mathrm{X}$ & \\
\hline dez & AAA & 1 & & & & $\mathrm{x}$ & & & & & & $x$ & & & & $\mathrm{x}$ & & & & & & $\mathrm{X}$ & & & & & $\mathrm{X}$ \\
\hline out & BBB & 2 & & & $\mathrm{X}$ & & & & & $\mathrm{X}$ & & & & & & $\mathrm{x}$ & & & & & $\mathrm{x}$ & & & & $\mathrm{X}$ & & \\
\hline dez & BBB & 2 & & & & $\mathrm{X}$ & & & & $\mathrm{X}$ & & & & & & $\mathrm{x}$ & & & & & $x$ & & & & & $\mathrm{X}$ & \\
\hline out & $\overline{C C C}$ & 3 & & & & $x$ & & & & $x$ & & & & & & $\mathrm{x}$ & & & & $x$ & & & & & & $\mathrm{X}$ & \\
\hline dez & CCC & 3 & & & & $\mathrm{X}$ & & & & & $\mathrm{x}$ & & & & & $\mathrm{x}$ & & & & $X$ & & & & & & $\mathrm{X}$ & \\
\hline out & DDD & 3 & & & $x$ & & & & & $x$ & & & & & & $x$ & & & & $x$ & & & & & & $x$ & \\
\hline dez & DDD & 3 & & & & $\mathrm{X}$ & & & & & $\mathrm{X}$ & & & & & $\mathrm{X}$ & & & & & $\mathrm{X}$ & & & & & $X$ & \\
\hline out & EEE & 2 & & & & $\mathrm{X}$ & & & & & $\mathrm{x}$ & & & & & $x$ & & & $x$ & & & & & & $x$ & & \\
\hline dez & EEE & 2 & & & & & $\mathrm{X}$ & & & & $\mathrm{x}$ & & & & & $\mathrm{x}$ & & & & $x$ & & & & & & $X$ & \\
\hline out & FFF & 4 & & & $x$ & & & & & $x$ & & & & & & $\mathrm{x}$ & & & & & $x$ & & & & & 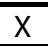 & \\
\hline dez & FFF & 4 & & & & $\mathrm{X}$ & & & & $\mathrm{X}$ & & & & & & & $x$ & & & & & $X$ & & & & $\mathrm{X}$ & \\
\hline
\end{tabular}

Tendo em vista que todos os funcionários apresentaram melhorias nos itens avaliados, pode-se afirmar que o feedback serviu como estímulo para melhoria de toda a equipe. Os resultados das avaliações de desempenho somados a outros indicadores podem servir como subsídio para a gestão de pessoas, a partir dos quais pode-se planejar treinamentos nos itens com menor pontuação, manter as ações desenvolvidas nos itens com pontuação maior, bem como utilizar estas informações como pré-requisito no sistema de remuneração. Os itens considerados na avaliação de desempenho utilizada na pesquisa foram sugeridos pelos responsáveis dos RHs e Técnicos em Segurança das empresas participantes da pesquisa.

\subsection{Aplicação de treinamentos ministrados pelo gestor de obra, aos seus colaboradores, no canteiro de} obras

O número de horas treinadas por funcionário/mês na Empresa $C$ foi 1,33 horas e na Empresa $D$ 1,23 horas. Percebeu-se durante a pesquisa que nas empresas " $A$ " $\mathrm{e}$ " $B$ " foram encontradas dificuldades na aplicação do procedimento devido às características dos respectivos gestores de obras (grau de instrução, resistência às mudanças e indisponibilidade), os quais possuíam conhecimento prático das atividades, mas tinham dificuldades para repassar aos subordinados através de treinamentos formais. Verificou-se que os gestores repassavam verbalmente as instruções para os subordinados no local da realização das tarefas, com exceção dos treinamentos de segurança no trabalho que eram ministrados em conjunto com o técnico em segurança no trabalho.

\subsection{Envolvimento do gestor de obra na definição das normas internas da empresa}

Este procedimento foi aplicado em todas as empresas, sendo que na Empresa A o percentual de participação do gestor foi de $80 \%$, enquanto nas demais empresas foi de $100 \%$. Durante a pesquisa percebeuse que, mesmo tendo sido alto o percentual de participação do gestor de obra na definição das normas internas, em nenhuma das empresas havia um procedimento formal para registro e transmissão das normas aos empregados. No dia a dia as novas regras eram repassadas verbalmente nas reuniões do setor de trabalho e/ou comunicados expostos nos quadros de avisos.

\subsection{Comprometimento do gestor de obra na fiscalização do cumprimento das normas internas}


Observou-se que o procedimento (Lista de Verificações de Inspeção da Obra) foi aplicado em todas as empresas, sendo que na Empresa A foram registradas 3 ocorrências, na Empresa B 5 ocorrências, na Empresa C uma ocorrência e na Empresa D 4 ocorrências. O resultado da aplicação deste procedimento revelou que a informalidade das normas internas, deficiência na comunicação aos empregados e a falta de fiscalização contribuem para o não cumprimento das normas internas.

\subsection{Envolvimento do gestor de obra nos trabalhos de gestão dos terceirizados}

A implementação deste procedimento evidenciou o não cumprimento das normas internas pelas empresas terceirizadas, seja por ignorância ou desconhecimento dessas normas. Percebeu-se que as não conformidades registradas estão relacionadas com procedimentos de saúde e segurança no trabalho.

Observou-se também que, em algumas empresas, a contratação de empresas terceirizadas ocorre de maneira informal, que geralmente são formalizados contratos apenas para trabalhos de maior valor, enquanto trabalhos de menor valor os contratos eram verbais. Em relação às normas internas da empresa contratante, raramente as empresas terceirizadas e seus empregados recebiam treinamento formal; as normas eram informadas verbalmente. Quando havia emissão de contrato formal algumas normas internas foram apenas citadas nos contratos. A informalidade na contratação de terceiros dificulta a exigência no cumprimento das normas internas pelo gestor de obra.

\section{DISCUSSÃO}

Através da aplicação desta pesquisa percebeu-se que o sistema de gestão de pessoas nas empresas é deficiente. Os resultados apresentados mostraram que os procedimentos adotados nas organizações geralmente eram informais, havendo pouca interação dos profissionais envolvidos no processo durante a realização das atividades respectivas. A falta de procedimentos padronizados foi uma carência observada em todas as empresas, não havendo indicadores de desempenho estruturados para servir de apoio na tomada de decisões.

Em relação aos profissionais envolvidos nos processos verificou-se pouca participação do gestor de obras, o qual era peça fundamental para o êxito na aplicação do modelo de gestão de pessoas sugerido. Quanto aos gestores de RH constatou-se que estes, embora tivessem as competências básicas para coordenar o sistema de gestão de pessoas, a sobrecarga de tarefas operacionais os limitavam em desenvolver ações de gestão, de modo que atuava como um assessor em gestão de pessoas aos demais setores da empresa, assim como corroborado por Marras (2005), Bichuetti (2011) e Zhai, Liu e Fellows (2014)

Os proprietários das empresas, por sua vez, consideraram serem importantes os procedimentos de gestão de pessoas em suas empresas, como pode se observar nas respostas dos questionários de diagnóstico aplicados; porém, na prática, percebeu-se que o sistema de gestão de pessoas ainda era carente em suas empresas. Essas constatações reforçam as teorias de que o assunto gestão de pessoas nas empresas é deixado em segundo plano, que por serem consideradas como atividades meio e não atividades fim, muitas vezes não são levadas em consideração nos planos estratégicos das empresas (ZHAl; LIU; FELLOWS, 2014; MELEK, 2016; DEMO; FOGAÇA; COSTA, 2018).

Referente ao modelo de indicadores proposto na pesquisa, percebe-se que não há complexidade na execução das atividades propostas, sendo de fácil assimilação e implementação, uma vez que, de maneira informal, atividades similares às propostas já vinham sendo executadas. Independentemente de haver alguma complexidade na execução dos procedimentos sugeridos, percebeu-se que aqueles que possuíam determinação legal eram facilmente cumpridos, como é o caso do treinamento de integração com os novos empregados que eram realizados em todas as empresas pesquisadas. Porém, isso não se repetia com os demais indicadores.

Os resultados obtidos na pesquisa apresentam informações importantes para a tomada de decisões estratégicas em gestão de pessoas. Os indicadores revelaram as carências do processo de gestão de pessoas sob forma de que a deficiência de uma atividade implica em deficiências de uma atividade seguinte. De 
maneira geral, percebeu-se que as constatações obtidas durante o período da pesquisa corroboram com os resultados de trabalhos realizados por diversos autores, os quais concluíram que há uma grande necessidade de formalização da gestão de pessoas na construção civil (SALGADO, 2011, TAVARES; LONGO; SUETH, 2014).

\section{CONCLUSÕES}

O estudo realizado teve por objetivo de criar e aplicar um modelo de indicadores de gestão de pessoas em pequenas e médias empresas da construção civil, sendo que a aplicação prática do modelo permitiu a coleta e análise dos respectivos indicadores de desempenho. Percebeu-se que nas empresas participantes da pesquisa não havia e/ou não utilizavam quaisquer indicadores de gestão de pessoas para tomada de decisões. Em função disso, havia várias deficiências, tais como: apenas $25 \%$ dos candidatos recrutados possuíam perfil para a vaga desejada; o perfil da vaga não era utilizada para desenvolver programas de capacitação interna nas empresas; as normas internas da empresa contratante não foram cumpridas pelas empresas terceirizadas, chegando a apresentar mais de $50 \%$ de não conformidade em uma das empresas.

Os dados fornecidos pelos indicadores mensurados na aplicação dos procedimentos mostraram que o modelo aplicado é relevante, sugerindo que pode ser utilizado pelas empresas como ferramenta de gestão, para se obter informações que subsidiem a alta direção das empresas e seus gestores na tomada de decisões estratégicas das organizações. Para tal, é imprescindível que as empresas adotem uma política de gestão de pessoas estruturada, sob forma de que todos os envolvidos no processo estejam comprometidos com os procedimentos estabelecidos.

\section{REFERÊNCIAS}

AMBERG, Joe J; MCGAUGHEY, Sara L. Strategic human resource management and inertia in the corporate entrepreneurship of a multinational enterprise. The International Journal of Human Resource Management, v. 30, n. 5, p. 759-779, mar. 2019.

BICHUETTI, Jose Carlos. Gestão de pessoas não é com o RH. São Paulo: Lafonte, 2011.

BOON, Corine; DEN HARTOG, Deanne N; LEPAK, David P. A Systematic Review of Human Resource Management Systems and Their Measurement. Journal of Management, v. 45, n. 6, p. 2498-2537, jul. 2019.

BORGES, Valmir Sales; BRANDÃO, Susany Sales; MARINHO, Eliane Costa Pinto. Análise da gestão de RH na construção civil: teoria x prática. Pesquisa operacional para o desenvolvimento, v. 2, n. 1, p. 1-86, jan./abr. 2010.

BRANDENBURG, Stefanie; HAAS, Carl T.; BYROM, Keith. Strategic Management of Human Resources in Construction. Journal of Management in Engineering, v. 22, n. 2, p. 89-96, abr. 2006.

BRASIL. Ministério do Trabalho e Emprego. Norma Regulamentadora 18: Condições e Meio Ambiente de Trabalho na Indústria da Construção. Brasília: MTE, 2018.

BROCKMAN, J. L. Interpersonal Conflict in Construction: Cost, Cause, and Consequence. Journal of Construction Engineering and Management, v. 140, n. 2, p. 1-12, fev. 2014.

CHEN, L.; MOHAMED, S. The strategic importance of tacit knowledge management activities in construction. Construction Innovation, v. 10, n. 2, p. 138-163, 2010.

CHIAVENATO, Idalberto. Gestão de pessoas: o novo papel dos recursos humanos nas organizações. 4. ed. Barueri: Manole, 2014. 
CHINOWSKY, P; CARRILLO, P. Knowledge Management to Learning Organization Connection. Journal of Management in Engineering, v. 23, n. 3, p. 122-130, jul. 2007.

CLARKE, Linda, HERMANN, Georg. Skill shortages, recruitment and retention in the house building sector. Personnel review, v. 36, n. 4, p. 509-527, 2007

DAINTY, Andrew; GRUGULIS, Irena; LANGFORD, David. Understanding construction employment: the need for a fresh research agenda. Personnel Review, v. 36, n. 4, p. 501-508, 2007.

DEMO, Gisela; FOGAÇA, Natasha; COSTA, Ana Carolina. Políticas e práticas de gestão de pessoas nas organizações: cenário da produção nacional de primeira linha e agenda de pesquisa. Cadernos EBAPE.BR, v. 16, n. 2, p. 250-263, abr./jun. 2018.

DOM, N. M.; KASIM, N.; SHAMSUDIN, A. Framework of human resource planning (HRP) influencing factors for local workforce supply in Malaysian construction industry. Journal of Technology Management in China, $\mathrm{v}$. 7, n. 2, p. 177-197, maio 2012.

ESMI, R.; ENNALS, R. Knowledge management in construction companies in the UK. Al \& Society, v. 24, n. 2, p. 197-203, mar. 2009.

IVANCEVICH, John M., Human Resource Management. 11. ed. Boston: Mc Graw Hill, 2010.

LAUFER, Alexander. Aptitude development of civil engineers for the management of human resources in construction projects. International Journal of Project Management, v. 5, n. 4, p. 209-216, nov. 1987.

MARRAS, Jean Pierre. Gestão de pessoas em empresas inovadoras. São Paulo: Futura, 2005.

MELEK, Marlos Augusto. Trabalhista! E Agora? Onde as empresas mais erram. Curitiba: Estudo Imediato Editora, 2016.

PATHIRAGE, C. P.; AMARATUNGA, D. G.; HAIGH, R. P. Tacit knowledge and organizational performance: construction industry perspective. Journal of Knowledge Management, v. 11, n. 1, p. 115-126, fev. 2007.

PEREIRA, V. R. Validação de um modelo de indicadores de gestão de pessoas em pequenas e médias empresas da construção civil. 2017. 142 f. Dissertação (Mestrado em Tecnologia e Gestão da Inovação) Universidade Comunitária da Região de Chapecó, Chapecó, 2018.

RAJA, J. Z.; GREEN, S. D., LEIRINGER, R.; DAINTY, A.; JOHNSTONE, S. Managing multiple forms of employment in the construction sector: implications for HRM. Human Resource Management Journal, v. 23, n. 3, p. 313328, jul. 2013.

SALGADO, Julio Cesar Pereira. O mestre de obras. In: SALGADO, Julio Cesar Pereira (org.). Mestre de obras: gestão básica para a construção civil. 1. ed. São Paulo: Érica, 2011. p. 19-25.

SAMPIERI, Roberto Hernández; COLLADO, Carlos Fernández; LUCIO, María del Pilar Baptista. Metodologia de Pesquisa. 5. ed. Porto Alegre: Mc Graw Hill, 2013.

TAVARES, Aureliano da Silva; LONGO, Orlando; SUETH, Robson. Conflitos na gestão de pessoas na construção civil: um estudo descritivo. In: SIMPOSIO DE EXCELENCIA EM GESTÃO E TECNOLOGIA, 11., 2014, Resende.

Anais Eletrônicos [...]. Resende: Associação Educacional Dom Bosco, 2014.

ZHAI, Xiaofeng; LIU, Anita M. M.; FELLOWS, Richard. Role of Human Resource Practices in Enhancing Organizational Learning in Chinese Construction Organizations. Journal of Management in Engineering, $v$. 30, n. 2, p. 194-204, mar./abr. 2014. 